\section{International Society for Pharmacoeconomics and Outcomes Research Comments on the American Society of Clinical Oncology Value Framework}

To THE Editor: As members of the International Society for Pharmacoeconomics and Outcomes Research, we read with great interest the new American Society of Clinical Oncology (ASCO) conceptual framework to assess the value of cancer treatment options. ${ }^{1}$ We applaud the Value in Cancer Care Task Force for proposing a conceptual framework to support clinicians and patients in assessing the value of new cancer treatments. We acknowledge the challenges facing clinician-patient decision making, particularly concerning cancer treatments. Like ASCO, we recognize that the cost of treatments is increasingly being placed on patients through cost sharing and that engaging patients as part of making individual treatment decisions is of high importance. The ASCO framework highlights the growing tension among patients, insurance companies, and product manufacturers in a dynamic health care environment. In that light, the framework deserves a field test, and we look forward to seeing the outcome of that experience. We also appreciate the opportunity to offer comments and suggestions on the ASCO framework at this early stage, and our membership stands ready to support ASCO in future enhancements.

In our view, the proposed framework focusing on the patient-physician dyad is an interesting approach and has some desirable elements, but also some important limitations. It would be helpful to clarify differences between a value framework to support physician-patient individual-level decision making and a framework that would operate more at a broader societal level. Indeed, the two perspectives are linked in that decisions made at the individual level, when aggregated, affect the resources available to the health care system, the overall cost of health care, and, ultimately, access and health outcomes that can be delivered to all patients. This reflects the need for health systems to consider cost effectiveness appropriately in decisions about funding, pricing, and reimbursement. The European Society of Medical Oncology, for example, created the Magnitude of Clinical Benefit Scale in an effort similar to that of the ASCO task force, but that approach takes into account whether benefit is curative or palliative and only applies to solid tumor types. ${ }^{2}$ Furthermore, validated measures of health-related quality of life are explicitly incorporated into the European Society of Medical Oncology approach.

Although the focus of the ASCO value framework is on the patient perspective, the article also notes that the physician "has a responsibility to be a good steward of health care resources."1(p2564) Clinical treatment guidelines that consider cost effectiveness and reflect differing health state valuations among patients can provide clinicians with a way to help resolve what might seem to be a conflict in these roles. We encourage ASCO to consider expanding its perspective, giving consideration to this broader framework when developing treatment guidelines.

Such an approach would be consonant with recent recommendations by the American College of Cardiology/American Heart Association to incorporate cost-effectiveness analysis into clinical treatment guideline development. ${ }^{3}$ Patients with serious cardiac disease face many of the same issues that patients with cancer face: severe limitations in functional status and quality of life, high mortality, and burden of treatment.

In its conceptual framework, the task force did not embrace the use of quality-adjusted life-years (QALYs). The authors noted concerns that the QALY may not fully capture all of the relevant attributes sufficiently, that there is no consensus on thresholds for incremental cost-effectiveness ratios, and that so-called health care rationing is implied. Although we recognize these points, the health economics and outcomes research field is substantially invested in using both QALYs and cost-effectiveness analyses as tools to support the difficult health care resource allocation decisions that societies face. For example, the Tufts Medical Center CostEffectiveness Analysis Registry ${ }^{4}$ catalogs more than 4,300 costutility analyses with valuations of patient health-related quality of life in more than 10,000 health states. We recognize that the direct usefulness of these tools for individual patients may be limited; however, we have suggestions concerning the definition of value criteria and the methods used to derive the weights and the resulting outcomes in the ASCO value framework. We would encourage that future research engage experts in multicriteria decision analysis to validate and revise the weights and, if necessary, incorporate individual patient preferences into the framework.

In summary, we applaud the efforts by ASCO to incorporate value assessments in an environment of constrained resources. As a leading society of health economists and outcomes researchers, the International Society for Pharmacoeconomics and Outcomes Research has developed more than 40 good practice guidelines related to health technology assessment. We invite ASCO and other societies to engage our members in the creation and validation of value assessment tools.

\section{Daniel C. Malone}

Colleges of Pharmacy and Public Health, University of Arizona, Tucson, AZ

\section{Nancy S. Berg}

International Society for Pharmacoeconomics and Outcomes Research, Lawrenceville, $\mathrm{N}$

\section{Karl Claxton}

University of York, York, United Kingdom

Louis P. Garrison Jr

University of Washington School of Pharmacy, Seattle, WA

\section{Maarten IJzerman}

University of Twente, Enschede, the Netherlands 


\section{Kevin Marsh}

Evidera, London, United Kingdom

Peter J. Neumann

Tufts Medical Center, Boston, MA

\section{Mark Sculpher}

University of York, York, United Kingdom

\section{Adrian Towse}

Office of Health Economics, London, United Kingdom

\section{Carin Uyl-de Groot}

Erasmus University Rotterdam, Rotterdam, the Netherlands

\section{Milton C. Weinstein}

Harvard T.H. Chan School of Public Health, Boston, MA

NOTE. The authors of the ASCO value framework have addressed these as well as other comments in the accompanying Special Article entitled "Updating the American Society of Clinical Oncology Value Framework: Revisions and Reflections in Response to Comments Received." 5
AUTHORS' DISCLOSURES OF POTENTIAL CONFLICTS OF INTEREST

Disclosures provided by the authors are available with this article at www.jco.org.

\section{REFERENCES}

1. Schnipper LE, Davidson NE, Wollins DS, et al: American Society of Clinical Oncology statement: A conceptual framework to assess the value of cancer treatment options. J Clin Oncol 33:2563-2577, 2015

2. Cherny NI, Sullivan R, Dafni U, et al: A standardised, generic, validated approach to stratify the magnitude of clinical benefit that can be anticipated from anti-cancer therapies: The European Society for Medical Oncology Magnitude of Clinical Benefit Scale (ESMO-MCBS). Ann Oncol 26:1547-1573, 2015

3. Anderson JL, Heidenreich PA, Barnett PG, et al: ACC/AHA statement on cost/value methodology in clinical practice guidelines and performance measures: A report of the American College of Cardiology/American Heart Association Task Force on Performance Measures and Task Force on Practice Guidelines. J Am Coll Cardiol 63:2304-2322, 2014

4. Tufts Medical Center, Center for the Evaluation of Value and Risk in Health: Cost-Effectiveness Analysis Registry. www.cearegistry.org

5. Schnipper LE, Davidson NE, Wollins DS, et al: Updating the American Society of Clinical Oncology value framework: Revisions and reflections in response to comments received. J Clin Oncol 34:2925-2934, 2016

DOI: 10.1200/JCO.2015.64.4328; published online ahead of print at www.jco.org on June 13, 2016. 
International Society for Pharmacoeconomics and Outcomes Research Comments on the American Society of Clinical Oncology Value Framework

The following represents disclosure information provided by authors of this manuscript. All relationships are considered compensated. Relationships are self-held unless noted. I = Immediate Family Member, Inst = My Institution. Relationships may not relate to the subject matter of this manuscript. For more information about ASCO's conflict of interest policy, please refer to www.asco.org/rwc or jco.ascopubs.org/site/ifc.

Daniel C. Malone

Consulting or Advisory Role: Biogen Idec, UCB, AstraZeneca, Genentech, Astellas Pharma

Nancy S. Berg

No relationship to disclose

\section{Karl Claxton}

Consulting or Advisory Role: Payer Evidence Council, Roche

Louis P. Garrison Jr

Honoraria: Roche, Novartis, Novo Nordisk

Consulting or Advisory Role: Roche, Novartis, Novo Nordisk

Speakers' Bureau: Roche, Novartis

Research Funding: Roche, Novartis, Pfizer

Other Relationship: Veritech

\section{Maarten Ijzerman}

Leadership: Panaxea

Stock or Other Ownership: Panaxea

Honoraria: Roche, Sanofi

Speakers' Bureau: Market Access Provider

\section{Kevin Marsh}

Consulting or Advisory Role: AstraZeneca, Boehringer Ingelheim, Biogen Idec, Biomarin, Celgene, Forest Laboratories, Genzyme, Novartis, Novo Nordisk, Pfizer, Roche, Sanofi, Shire, TEVA Pharmaceuticals Industries

\section{Peter Neumann}

Honoraria: Merck, Novartis, Bayer HealthCare Pharmaceuticals, UCB, Sanofi, Takeda Pharmaceuticals, Novo Nordisk

Consulting or Advisory Role: Boston Health Economics, Purdue Pharma Research Funding: Bayer HealthCare Pharmaceuticals (Inst), Genentech (Inst), Biogen Idec (Inst), Abbott Laboratories (Inst), Amgen (Inst), Sanofi (Inst), Johnson \& Johnson (Inst)

\section{Mark Sculpher}

Consulting or Advisory Role: Sanofi, GlaxoSmithKline, Medtronic, Eli Lilly, Roche, Merck Sharp \& Dohme, AbbVie, Novartis, ICON Clinical Research

\section{Adrian Towse}

Employment: Association of the British Pharmaceutical Industry Leadership: Association of the British Pharmaceutical Industry Research Funding: Roche (Inst)

\section{Carin Uyl-de Groot}

Research Funding: Boehringer Ingelheim (Inst), Janssen-Cilag (Inst), Astellas Pharma (Inst), Roche (Inst), Therakos (Inst), Amgen (Inst), Gilead Sciences (Inst), Merck Serono (Inst), Sanofi Pasteur (Inst), Bayer Schering Pharma (Inst)

Milton C. Weinstein

Consulting or Advisory Role: OptumInsight 